\section{COVID19 - The Catalyst for Educational Change: Applying/Using e-PBL for Accelerated Change}

\section{Margaret McMillan}

School of Nursing and Midwifery, University of Newcastle, Australia

Recently Cheju Halla University (CHU) demonstrated a willingness to embrace more blended forms of delivery including a greater reliance on e-learning. The catalyst for the change was COVID19, a major disruptor of all societal functions. This particular pandemic has led to a dramatic loss of human life worldwide and presents an unprecedented challenge to public health, food systems, education and the world of work (WHO 2020).

For the annual PBL conference this year, a webinar replaced the usual face-to face-face event. It was clear that $\mathrm{CHU}$ like the higher education sector elsewhere, was severely impacted by the pandemic. All stakeholders in higher education were caused to change by the spread of COVID19 (The Lancet 2020). Parties to the Tokyo Convention noted in November that the challenges of COVID-19 have made online and blended learning the new normal and sought to recognise online learning to prevent further disruption to students (Sharma, 2020).

Revolutionary change in education needed to happen quickly. The term 'digidemic' has been coined is to describe the rapid widespread digitalisation of learning that has affected many universities across the globe, where the traditional face-to-face teaching has been replaced with distanced teaching (Alam, 2020). However, some processes and people needed to change more than others. Key personnel in universities across the world knew that they needed to support students first and foremost in the COVID19 crisis if ongoing enrolment and completion of studies was to be assured. Moving towards more flexible modes of delivery and recognition that learning outcomes can be met in a variety of ways is essential (Sharma, 2020).

Problem-based Learning (PBL) curricula provide scaffolding for integration of ideas and facilitate modification of learning activities when necessary. Student-centered, self-directed and work-integrated Learning are features of PBL, but e-Learning platforms would need to be developed in a way that aligns with PBL curriculum design.

From the conference papers it was easy to see that a case study centered on population and preventive health would be a useful addition for student learning. Presentations centered on the manner in which

- Change in approaches to learning was an imperative in the circumstances imposed by a pandemic

- PBL frameworks facilitated rapid responses such as the capacity to move towards more student-centered and self-directed learning

- Actual case studies within the webinar demonstrated the desired graduate abilities such as problem-framing and solving, therapeutic intent, critical appraisal of novel situations, meaningful communication, collaborative practice, giving and responding to feedback and information literacy.

- There was a need for mental health support for students and others impacted by changing circumstances.

- Paradigmatic shifts are impacted by culture but can feature cultural nuances around ethical

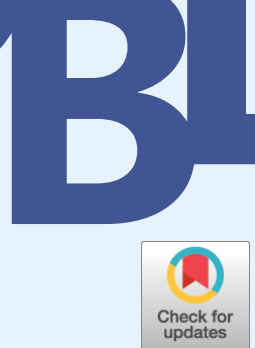

Editorial

pISSN 2288-8675 · elSSN 2508-9145

J Probl Based Learn 2020;7(2):51-52

https://doi.org/10.24313/jpbl.2020.00297

Received: October 17, 2020

Accepted: October 29, 2020

Corresponding author:

Margaret McMillan

School of Nursing and Midwifery,

University of Newcastle, 66 Rickard

Street, Bateau Bay, NSW 2261,

Australia

Tel: +61-408-431269

E-mail:margaret.mcmillan@

newcastle.edu.au
(C) Copyright 2020 International Society for Problem-Based Learning

(c) This is an Open Access article distributed under the terms of the Creative Commons Attribution Non-Commercial License (http://creativecommons.org/licenses/ by-nc/4.0/) which permits unrestricted non-commercial use, distribution, and reproduction in any medium, provided the original work is properly cited. 
dilemmas for older people managing life transitions.

- There was a need for differentiation across academic and technical roles in educational design initiatives.

- A digital future that we had not fully embraced, was now more desirable and possible.

- A vision for educational change must be a shared one and be backed with sufficient resources.

It is clear that information literacy is more important now than it ever was and must be a feature of curriculum design and implementation in a way that prepares students for the real world. Generally, students globally have responded well to changes imposed by COVID19, because they were natives of the digital age. But some still needed support (Aristovnik et al. 2020). There was a clear demonstration of a need to cause students to embrace student-centered and self-directed learning in a way that helps prepare them for work and life where reliance on technology is now a feature of most transactions.

During the on-line symposium, it was shown that the professional development of academics (with the teacher as learner) was also needed for existing and new generations of staff members if curriculum renewal efforts were to pivot successfully (Little \& McMillan 2019). It is desirable that some of this professional development also be conducted on-line and reflect the values and principles of PBL. Teachers need to appreciate student experiences with self-directed and student- centered learning.

The key to achieving contemporary student-centered learning outcomes that reflect the abilities needed in real life, is in sound educational design, especially the use of authentic case studies. On-line PBL allows for a broad range of stimulus material to be used and changed when necessary.

My son is a mature-age paramedic student in his final year of a program using PBL in an on-line mode offered to 200 students for the first time within that particular Australian University. When COVID19 struck, 400 on-campus students had to pivot to the on-line mode. The major impact for his student cohort was the inclusion of the larger group in the e-learning environment. The most negative impact for the original on-line group arose from the expansion of the student group. What changed often as a result of the need to ensure sound population health during COVID 19 were the assessment tasks. It is important reminder that for students, assessment equates to learning if it does what it says it will do. Therefore, there is a need to ask 'If I use this assessment task, what learning outcomes am I causing the students to demonstrate?' Much of what we do on-campus can be effectively reconfigured to place the learning event in the digi- tal space. This includes assessment tasks that assure the students that their learning outcomes have been realized.

My key messages here are that educational design matters irrespective of that nature and extent of the use of technology and that teachers are learners too. They need to share the vision for student learning processes and the values and principles underpinning the design and implementation of any curriculum philosophy. Professional development should include the use of the same methodology that we argue is necessary for contemporary students in the digital age. Personal reflections on the webinar experience suggest that the exercise was successful and provided powerful and moving teachable moments. The webinar organizers and participants were able to show how curriculum renewal is possible while retaining the integrity of the PBL framework. Live interactions through facilities for question and answer and chat lines demonstrated a high level of engagement.

\section{REFERENCES}

Aristovnik, A., Keržič, D., Ravšelj, D., Tomaževič, N., \& Umek, L. (2020). Impacts of the COVID-19 Pandemic on Life of Higher Education Students: A Global Perspective https://www.researchgate.net/publication/343555357.

Deloitte Center for Higher Education Excellence. (2020). COVID19's impact on higher education: Strategies for tackling the financial challenges facing colleges and universities https://www2.deloitte.com/content/dam/Deloitte/us/Documents/public-sector/us-gps-covid-19-impact-on-higher-education.pdf.

Little, P., \& McMillan, M. (2019). The teacher as learner: Professional development Programs as Agents for change. Journal of Problem-based Learning, 6(2), 59-66.

McMillan, M., \& Little, P. (2019). Learning outcomes for contemporary and future practice: Are we there yet? Journal of Problem-based Learning, 6(2), 45-46.

McMillan, M., \& Little, P. (2019). Curriculum design and implementation: Resources, processes and Results. Journal of Problem-based Learning, 6(2), 47-53.

News, The Lancet, Vol 21, June 2020, COVID-19: Consequences for higher education https://www.thelancet.com/pdfs/journals/ lanonc/PIIS1470-2045(20)30287-4.pdf.

Sharma, Y. (2020). Tokyo Convention parties want online learning recognized. https://www.universityworldnews.com/post.php?story $=20201111082338118$.

World Health Organization (WHO). (2020). COVID19 Update, https://covid19.who.int/. 